Indian J Anim Health (2021), 60(1) : 101-102

DOI:10.36062/ijah.60.1.2021.101-102

\title{
Per-vaginal delivery of emphysematous fetus in Punganur cow: A case report
}

\author{
A. Teja ${ }^{1 *}$, L. Phanikumar ${ }^{2}$, C. G. Varma ${ }^{3}$ and P. Tharangini ${ }^{1}$ \\ ${ }^{1}$ Department of Veterinary Gynaecology and Obstetrics, Sri Venkateswara Veterinary University, \\ Tirupati - 517 502, Andhra Pradesh, India; ${ }^{2}$ Veterinary Dispensary, Department of AH, Achanta, \\ West Godavari - 534 123, Andhra Pradesh, India; ${ }^{3}$ Veterinary Dispensary, Department of AH, Dimili, \\ Visakhapatnam - 531 061; Andhra Pradesh, India
}

\begin{abstract}
A full term pregnant Punganur cow was presented to the veterinary hospital with both the fetal forelimbs impacted in the birth canal. Gyneco-clinical examination revealed long standing dystocia, with foul smelling, large sized dead foetus at birth canal. Hence, the case was diagnosed as dystocia due to emphysematous fetus and feto-pelvic disproportion. Proper lubrication of birth canal and the fetus was done by using carboxyl methyl cellulose sodium. The limbs were repelled into the uterus, then decapitation was done and finally dead fetus was delivered by applying gentle traction. Uneventful recovery of the dam was noticed after delivery.
\end{abstract}

Key words: Dystocia, Emphysematous fetus, Fetotomy, Punganur cow

Fetal emphysema is a frequent complication of parturition and primary cause of dystocia in farm animals (Noakes et al., 2019). It is characterized by formation of gases in subcutaneous tissue within 24-72 hours causing fetal death and foetus becomes soft, decomposed and distended with gases (Sane et al., 1994). Feto-pelvic disproportion refers to the inability of the fetal head to pass through the maternal pelvis; it occurs in $1 \%$ to $3 \%$ of all primigravids (Roberts, 1986). The present case described the obstetrical procedure of partial fetotomy to relieve the emphysematous fetus.

A rare case of dystocia in Punganur cow due to emphysematous fetus and feto-pelvic disproportion was presented to the veterinary hospital with the history of completed gestation period subsequently parturition failure. The case was handled by the para veterinarians locally but failed to relieve the dystocia. Cold extremities, weakness, dehydration, dullness, suspended rumination, loss of appetite, continuous straining, foetid vaginal bleeding mixed with uterine contents were observed. The cow was in lateral recumbency. Per vaginal examination revealed partially dried vaginal passage, fully dilated cervix, large sized dead fetus and narrow pelvis.

Initially the cow was stabilised by administration of intravenous fluids and parenteral administration of NSAID and antihistamines. Epidural anaesthesia was performed with $7 \mathrm{~mL}$ of $2 \%$ lignocaine hydrochloride administered at $1^{\text {st }}$ intercoccygeal space. Later, the birth canal was lubricated with carboxyl methyl cellulose (CMC) @ 20 gm per liter of luke warm water. As the birth canal was narrower than swollen emphysematous fetus, it was decided to perform partial fetotomy. Longitudinal incisions with BP blade no. 22 were made on head in order to release gases. It helped in creating space in the pelvis. Fetal skin was separated around the neck and rope was tied by forced traction, head was removed (by decapitation) and then the fetus was removed from the birth canal (Fig. 1). After successful delivery of fetus by partial fetotomy, the dam was treated with Inj. Dextrose 5\%

*Corresponding Author 
Indian Journal of Animal Health, June, 2021

Dystocia due to emphysematous fetus in Punganur cow

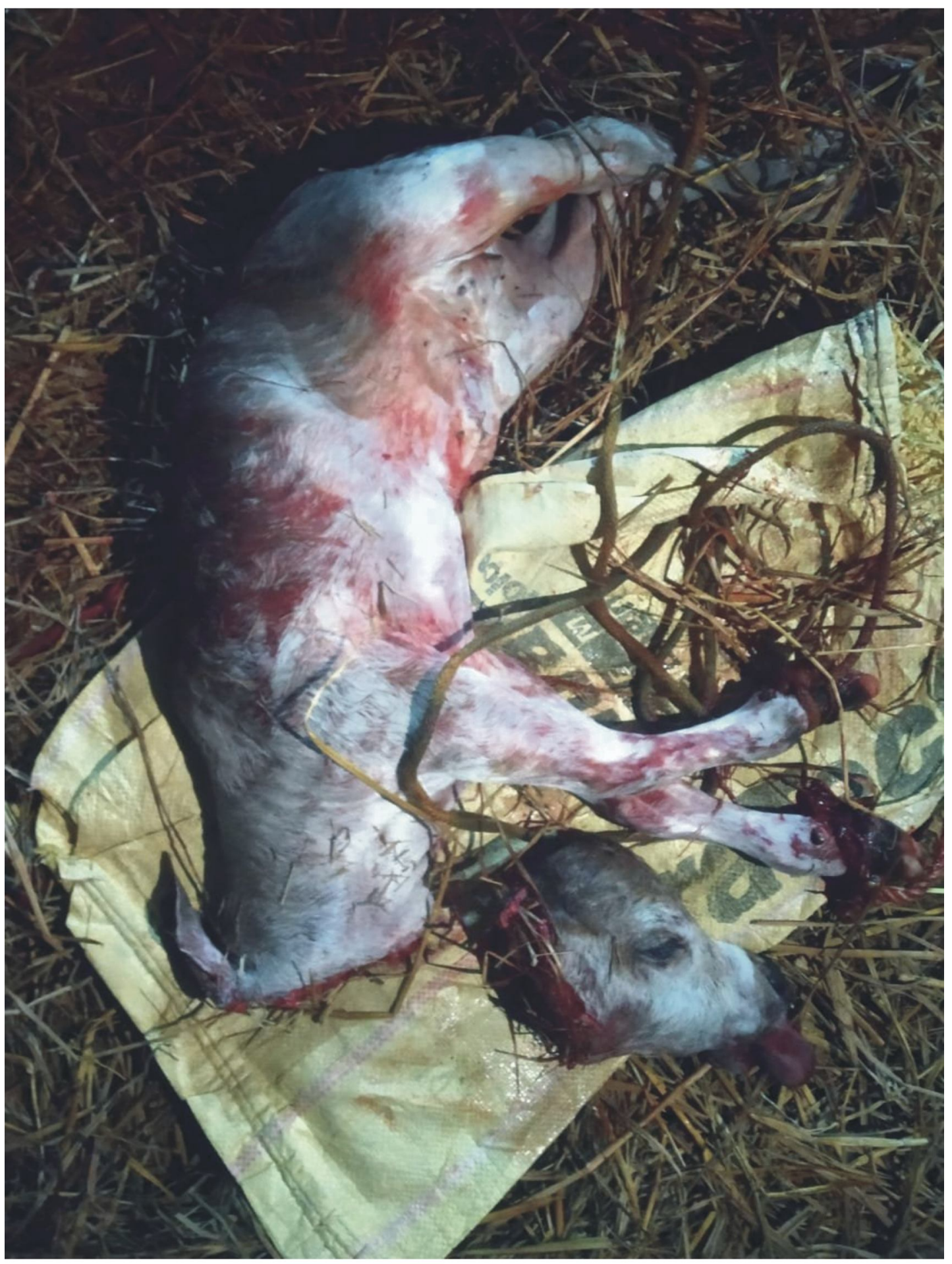

Fig. 1. Decapitated emphysematosed fetal calf 
@ 2 litres I/V, Inj. Intamox (amoxicillin and cloxacillin)@2.5 gm, Inj. meloxicam (Melonexa)@10 mL, Inj. chlorpheniramine maleate@8 mL I/M, Inj. Mifex@450 mL I/V and Inj. Tribivet (Vitamin B1, B6 and B12)@

\section{REFERENCES}

Noakes DE, Parkinson TJ and England GCW, 2019. Veterinary Reproduction and Obstetrics, $10^{\text {th }}$ edn., Elsevier Health Sciences WB Saunders Company Ltd., London, England, pp 294

Roberts SJ, 1986. Veterinary Obstetrics and Genital
$8 \mathrm{~mL} \mathrm{I} / \mathrm{M}$ for next five days. After the treatment, dam recovered uneventfully.

Conflict of interest: Authors have no conflict of interest in this study.

Diseases, $3^{\text {rd }}$ edn., CBS Publishers New Delhi, pp 281

Sane CR, Deshpande BR, Kaikini AS, Velhankar DP, Kodagali SB et al., 1994. Reproduction in Farm Animals, $2^{\text {nd }}$ edn., Varghese Publishing House, Bombay, India, pp 97 